\title{
Polyhedral Oligomeric Silsesquioxane (POSS) as Reinforcing Agent for Waterborne Polyurethane Coatings on Wood
}

\author{
Shuangying Wei, ${ }^{b},{ }^{\oplus}$, Linlong Meng ${ }^{b}$, Wenlong Liu ${ }^{a}$, Shiwei Guo ${ }^{b}$, Xingwen Zhang ${ }^{a}$ * \\ ${ }^{a}$ School of Chemistry and Chemical Engineering, Harbin Institute of Technology, Harbin 150001, China \\ ${ }^{b}$ College of Material Science and Engineering, Northeast Forestry University, Harbin 150040, China \\ 'Key Laboratory of Bio-based Material Science and Technology, Northeast Forestry University, Harbin \\ 150040, China
}

Received: April 15, 2018; Revised: November 27, 2018; Accepted: January 07, 2019

\begin{abstract}
Polyhedral oligomeric silsesquioxane (POSS) was added as a reinforcing agent in waterborne polyurethane (WPU)-based coatings to improve their properties. The morphology, structure, thermal stability as well as mechanical properties of the resulting WPU and WPU/POSS hybrid films were investigated. The good compatibility of POSS in the WPU matrices was demonstrated by transmission electron microscopy. Furthermore, Fourier-transform infrared spectroscopy analysis (FTIR) suggested the successful bonding of POSS and WPU matrices. The thermal stability of WPU/POSS hybrids was improved than that of pure WPU according to thermal gravimetric analysis (TGA). The results also revealed the enhancement of the pencil hardness and abrasion resistance of the hybrid films compared with WPU. However, the pull-off adhesion slightly decreased from Grade 0 to Grade 2.
\end{abstract}

Keywords: Polyhedral oligomeric silsesqui-oxane (POSS), Compatibility, Waterborne polyurethane(WPU), Hybrid film, Wood coatings.

\section{Introduction}

In recent years, the massive replacement of conventional solvent-based polyurethanes (PUs) wood coatings has occurred because of their adverse environmental effects. Waterborne polyurethanes (WPUs) exhibit outstanding environment-friendly features compared with conventional organic-solvent-based PUs. However, limitations such as their lower mechanical strength and thermal stability than those of organic-solventbased PUs have restricted their application. These issues have gradually been overcome with recent extensive studies of organic-inorganic nanocomposites that exhibit the combined characteristics of organic polymers (e.g. flexibility, ductility and dielectric property) and inorganic materials (e.g. rigidity, high thermal stability, strength, hardness and high refractive index) ${ }^{1}$, thus leading to their wide application.

Effective ways of improving the properties of WPUs include the chemical modification of their structures and hybridisation with nanomaterials ${ }^{2,3}$. Molecular chemical modification either changes the hard and soft segments of WPUs or introduces chemical crosslinks ${ }^{4}$. Nanomaterials are divided into inorganic materials such as clay ${ }^{5}$, silica, ${ }^{6}$ graphene ${ }^{7}$ and various nanoparticles such as $\mathrm{ZnO}^{8}$, $\mathrm{Fe}_{2} \mathrm{O}_{3}{ }^{9}$ and $\mathrm{Al}_{2} \mathrm{O}_{3}{ }^{10}$, which give the film high hardness, rigidity, thermal stability, strength, refractive index, abrasion resistance as well as scratch resistance ${ }^{11-12}$. However, the poor sanding behaviour of the coatings has negative effects such as limiting the repairability of pre-finished parquet flooring. Therefore, instead of inorganic fillers, organic polymers

*e-mail: zhxwhit@aliyun.com. such as polyacrylate ${ }^{13}$, vinyl acetate-acrylic ${ }^{14}$, cellulose ${ }^{15-17}$, starch $^{18}$ and chitosan ${ }^{19}$ have been studied. Furthermore, bio-based nanomaterials such as nanofibrillated cellulose have been studied as reinforcing filler for a wide range of polymer matrices because of their network structure and high stiffness ${ }^{20-35}$.

A functional organic/inorganic hybrid material has attracted widespread interest. The synergistic combination of organic polymers and inorganic silica has received considerable attention because of the potential for the development of new materials with designed properties by molecularlevel structural manipulation ${ }^{36-42}$, specifically, polyhedral oligomeric silsesquioxane (POSS)-based hybrid polymers have emerged as unique materials for various applications. The empirical formula of POSS nanostructure is $\mathrm{RSiO}_{1.5}$ The core of POSS is a silica cage consisting of $\mathrm{Si}-\mathrm{O}-\mathrm{Si}$, and the shell layer consists of organic reactive groups that can be compounded with polymers at the molecular level, thus forming a molecular organic/inorganic hybrid. The unique properties of POSS result in a strong interaction between the organic and inorganic components ${ }^{43-49}$.

Waterborne polyurethane (WPU) coatings are one of the most important coatings for protecting wooden substrates. However, utilizing POSS as reinforcing agent to tailor the properties of WPU coatings and overcome its weakness is still rare. In this work, POSS with a Si-O-Si cage structure and active functional groups such as epoxy and $\mathrm{Si}-\mathrm{OH}$ are first prepared via a sol-gel method. Inducing POSS to WPU wood coatings increase the crosslinking density between organic/inorganic moieties and urethane or hydroxyl groups 
in it. The effects of POSS on the structure, morphology, mechanical properties, thermal stability and performance of the coatings are investigated. The aim is to fabricate a hard, abrasion-resistant organic-inorganic hybrid barrier film for wood coating applications to improve the thermal stability, hardness and stiffness of it.

\section{Material and Methods}

\subsection{Materials}

Commercial 2,3-epoxypropoxy propyltrimethoxysilicane (silane coupling agent $\mathrm{KH}-560)$, ethanol $\left(\mathrm{C}_{2} \mathrm{H}_{5} \mathrm{OH}, 99.7 \%\right.$ ) and formic acid ( $\mathrm{HCOOH}, 98 \%$ ) were purchased from Youpu Chemistry Company (Nanjing, China).

A waterborne polyacrylic secondary dispersion (Bayhydrol A 2651, 3\% OH content on solids) and an anionically modified hexamethylene diisocyanate polyisocyanate (Bayhydrol XP 2655) waterborne curing agent were purchased from Bayer Materials Science \& Technology Co. Ltd. (China). Tego Airex 902W and Tego Foamex 810 were obtained from Evonik Industries AG (Shanghai, China). BYK-333 and BYK-345 were purchased from BYK Additives Company (Beijing, China). Ethylene glycol butyl ether was purchased from Chisheng Company of Tianjin (Tianjin, China). Deionized water was prepared in the laboratory.

\subsection{Preparation of POSS}

KH-560 was used as a precursor for hydrolytic condensation by using the sol-gel method. Distilled water and ethanol were used as solvents, and formic acid was used as a catalyst. KH-560 was placed in beakers, which were then placed in a water bath with $\mathrm{HCOOH}$ in a molar ratio of $\mathrm{KH}-560$ / ethanol $=1 / 3, \mathrm{KH}-560 /$ distilled water $=1 / 3$ and $\mathrm{HCOOH} /$ $\mathrm{KH}-560=1 / 50$. The reaction was performed in three stages: 1) plastic films were used to seal the beakers for six days; 2) several small needle-sized holes were made on the films for another one day; and 3) the film was removed, and the reaction was continued for four days. The temperature at every step was held at $35^{\circ} \mathrm{C}$. POSS synthesized this way was a mixture and was characterized by UV-MALDI-TOF $\mathrm{MS}^{50}$ to obtain an accurate description of the main species present in the silsesquioxane, as shown in Fig. 1. Table 1 shows the assignment of peaks which intensity is higher than $70 \%$. Theoretical masses were calculated using the average isotopic composition of the proposed compounds. The agreement between theoretical and experimental values is excellent and comprised within the experimental error of the technique. As indicated in Table 1, a possible isomer of the key species $\mathrm{T}_{8}$ is used as an example to illustrate the POSS structure in Fig. 2.

\subsection{Preparation of WPU/POSS hybrids}

Bayhydrol A 2651 and Bayhydrol XP 2655 were stirred at room temperature for approximately $20 \mathrm{~min}$, and a defoamer, surfactant, dispersant and thickener were added to synthesise the WPU coatings. The viscous transparent POSS gel was slowly added to WPU stirring at $300 \mathrm{rpm}$ at room temperature until the gel was evenly dispersed. The $\mathrm{pH}$ value was adjusted in the range of $\mathrm{pH} 8$ to $\mathrm{pH} 9$ by using the basic compound, and the material was adjusted to fit the viscosity requirements.

\subsection{Coating application on wood surface}

For the preparation of the wood coatings, the WPU/POSS suspensions were coated on wood samples by using a $300-\mu \mathrm{m}$ metering rod and then dried at $25^{\circ} \mathrm{C}-30{ }^{\circ} \mathrm{C}$. The thicknesses of the resulting wood coatings were approximately $60 \mu \mathrm{m}$. The WPU/POSS synthesis process and chemical structure of the hybrid material are shown in Fig. 3.

\subsection{Characterization and measurements}

The morphology of POSS particles in water and WPU coatings with $5 \mathrm{wt} \%$ loading and $10 \mathrm{wt} \%$ loading was examined using transmission electron microscopy (TEM; JEM-2100, Japan Electronics Corporation). Particles were stained with a solution of $2 \mathrm{wt} \%$ phosphotungstic acid. Hybrid materials were diluted to $0.1 \mathrm{wt} \%$ solids content. Micrographs were obtained after the specimens were stained. The structures of WPU and WPU/POSS coatings were analysed using Fouriertransform infrared (FT-IR) spectroscopy (Magna-IR560 E.S.P, Nicolet Company) and collected in the wavenumber range from $500 \mathrm{~cm}^{-1}$ to $4,000 \mathrm{~cm}^{-1}$ with a resolution of 4 $\mathrm{cm}^{-1}$ under reflection mode. The number of scans was 32 for each spectrum. A thermal gravimetric analyser (PerkinElmer, TGA-7) was used to investigate the thermal stability of the hybrids. The samples were heated in an air atmosphere from ambient temperature to $600{ }^{\circ} \mathrm{C}$ at a heating rate of $20^{\circ} \mathrm{C} /$ $\mathrm{min}$, and the gas flow rate was maintained at $50 \mathrm{~mL} / \mathrm{min}$. The mechanical properties of the WPU-based films were evaluated using nano-indentation (Nano indenter G200, Agilent Technologies Company) with a pressed depth of $5 \mu \mathrm{m}$. The average value of at least five replicates for each sample was obtained following ASTM D1474 ${ }^{51}$. The abrasion resistance, pencil hardness and pull-off adhesion properties of the WPU and WPU/POSS coatings were measured according to GBT4893.8-2013, GB/T 6739-2006 and GBT4893.4-2013 (GT 0 = no spalling, GT 5 = complete spalling), respectively. Pencil hardness was determined using a QHQ-A pencil hardness apparatus (Tianjin Instrument Co., China). Pull-off adhesion test was performed with a cross-cut apparatus (BYK-5213, Germany). The abrasion 


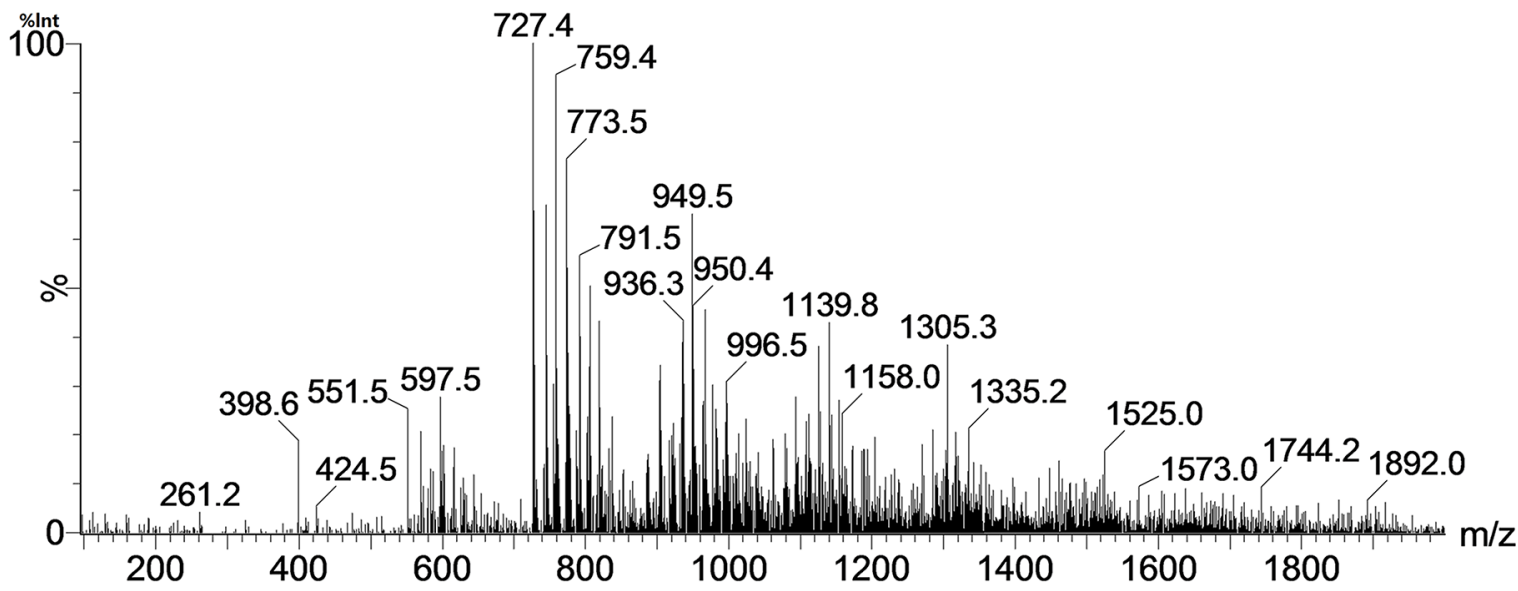

Figure 1. UV-MALDI-TOF MS of POSS

Table 1. Assignments of GP structures based on UV-MALDI-TOF MS data

\begin{tabular}{ccccc}
\hline Exptl. $\mathbf{~ m} / \mathbf{z}$ & $\mathbf{z}$ & Intensity & Assignment & Predicted $(\mathbf{M}+\mathbf{z H}+) / \mathbf{z}$ \\
\hline 727.4 & 2 & 100 & $\mathrm{~T}_{8}\left[\mathrm{H}_{2} \mathrm{O}\right]_{6} 2 \mathrm{H}^{+}$ & 728.1 \\
759.4 & 2 & 92 & $\mathrm{~T}_{8}(\mathrm{OH})_{2}\left(\mathrm{OCH}_{3}\right)_{2}\left[\mathrm{H}_{2} \mathrm{O}\right]_{6} 2 \mathrm{H}^{+}$ & 760.1 \\
773.5 & 2 & 75 & $\mathrm{~T}_{8}\left(\mathrm{OCH}_{3}\right)_{4}\left[\mathrm{H}_{2} \mathrm{O}_{6} 2 \mathrm{H}^{+}\right.$ & 774.2 \\
\hline
\end{tabular}<smiles>CO[Si](CCCOCC1CO1)(OC)OC</smiles>
POSS

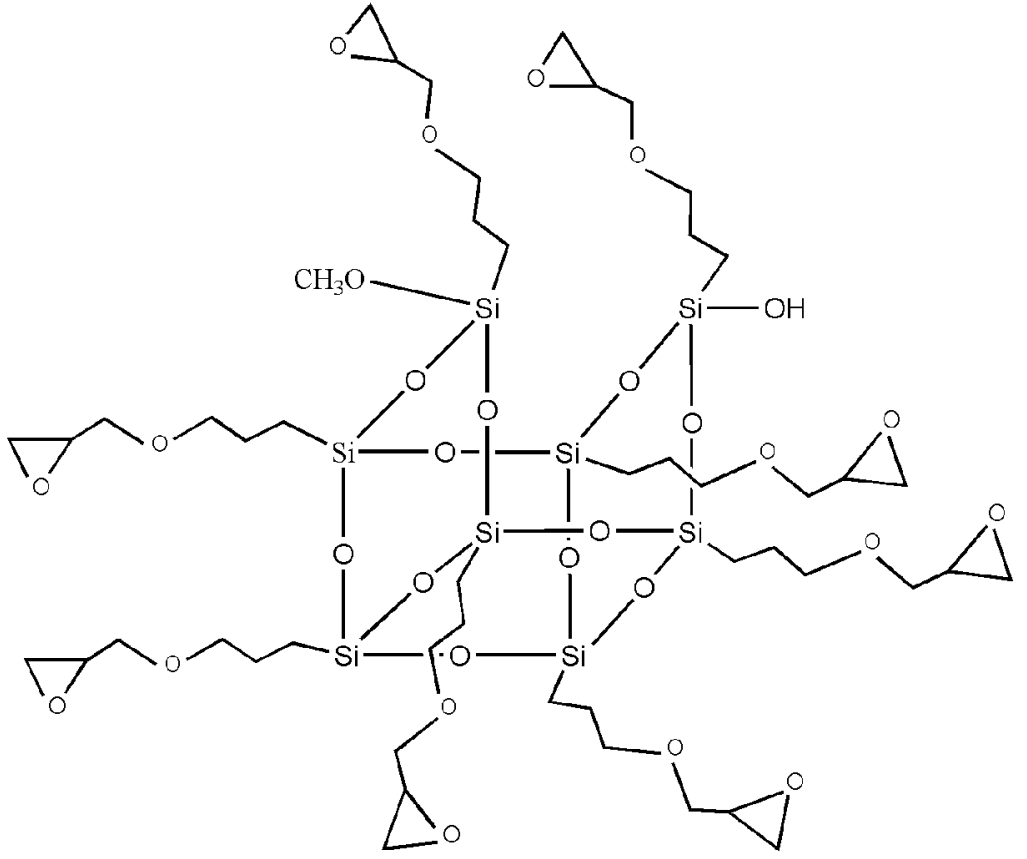

Figure 2. Schematic of the synthesis of POSS 

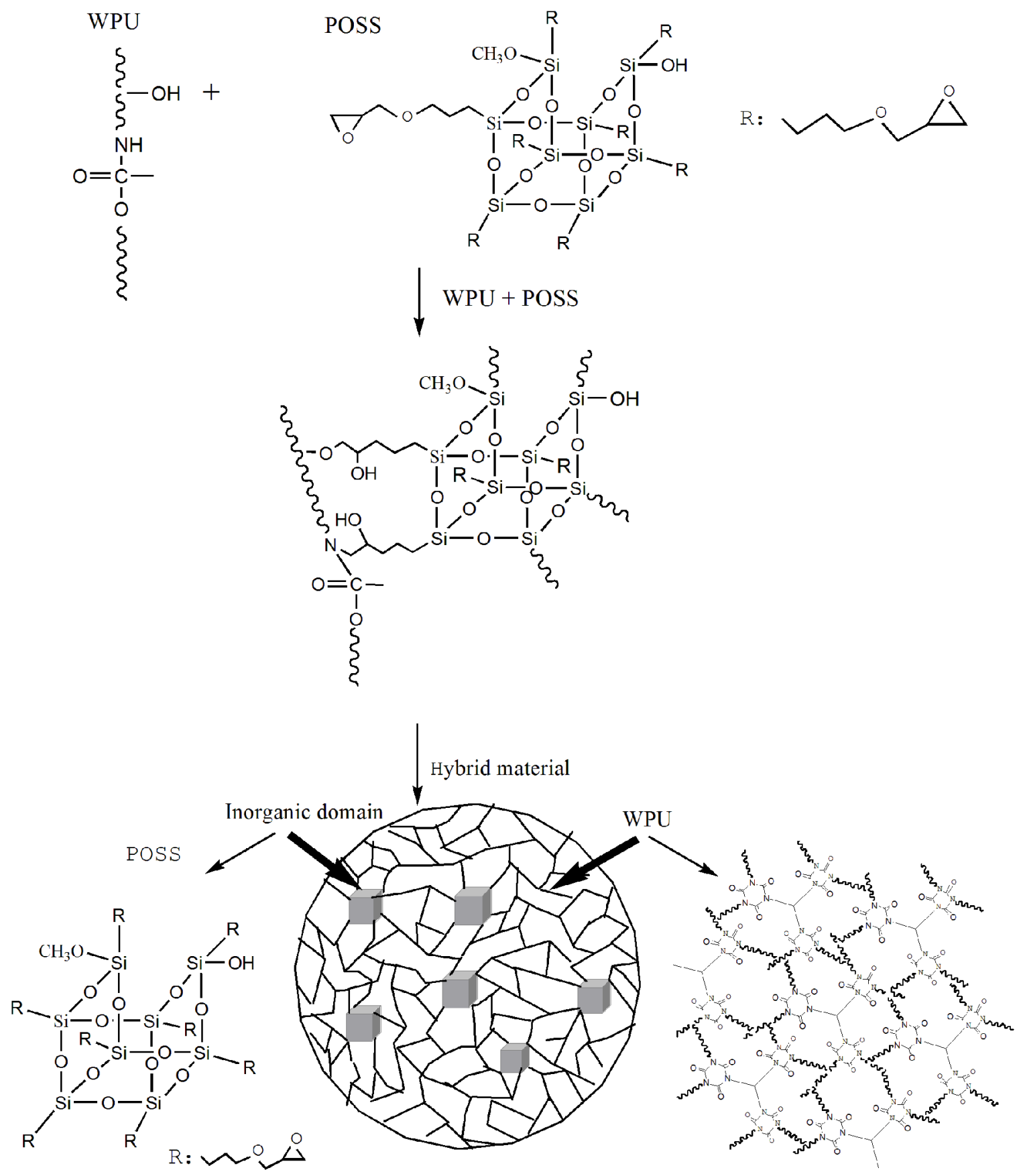

Figure 3. Schematic diagram of synthesis of hybrid material 
resistance was measured with an abrasion tester (Kunshan Jiesite Instrument Co., China).

\section{Results and Discussion}

\subsection{Structures of WPU and WPU/POSS hybrid films}

The FT-IR spectra of the cured pure WPU, WPU/POSS$5 \mathrm{wt} \%$ and POSS are presented in Fig. 4. The wide bands between 3300 and $3500 \mathrm{~cm}^{-1}$ in Figs. 4(a) and 4(b) were attributed to the presence of the stretching vibration of $\mathrm{N}-\mathrm{H}$ and $\mathrm{O}-\mathrm{H}$ bonds and interactions hydrogen bonds between functional groups such as amine, hydroxyl and carbonyl $1^{48-50}$. Furthermore, the bands at $1690 \mathrm{~cm}^{-1}$ were attributed to the stretching vibration of $\mathrm{C}=\mathrm{O}$ in the urethane group. The peaks at 907 and $847 \mathrm{~cm}^{-1}$ in Fig. 4(c) are characteristic peaks of epoxy groups; however, in Fig.4(b), the peak at $907 \mathrm{~cm}^{-1}$ completely disappeared, and the peak at $847 \mathrm{~cm}^{-1}$ significantly decreased. This finding indicates that the epoxy group as the active functional group in POSS reacted with the-NH-and -OH groups in the WPU/POSS hybrid film via a ring-opening reaction. The absorption peak at 1158 $\mathrm{cm}^{-1}$ is ascribed to the stretching vibration of C-O-C. This absorption peak was introduced by epoxy groups reacting with hydroxyl on WPU chain. Also, the peak that appeared at $1080 \mathrm{~cm}^{-1}$ is attributed to the stretching vibration of $\mathrm{Si}$ $\mathrm{O}-\mathrm{C}$. This peak is the result of the reaction of $\mathrm{Si}-\mathrm{OH}$ and -NCO. The absorption peak of the stretching vibration of $\mathrm{C}-\mathrm{N}$ at $1360 \mathrm{~cm}^{-1}$ in Fig. 4(b) which is due to the urethane group in WPU reacting with epoxy groups in POSS, is more intense than that in Fig. 4(a).

\subsection{Thermal stability of WPU and WPU/POSS films}

Fig. 5(a) and Fig. 5(b) present the TGA curves and their derivative curves (DTG), respectively, for the WPU, POSS and WPU/POSS hybrid films with different POSS loadings and shows their thermal decomposition behaviours.

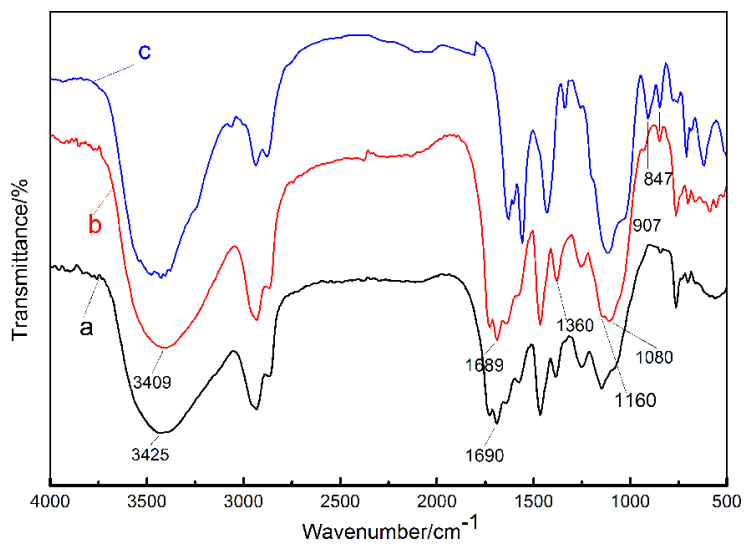

Figure 4. FT-IR spectra of (a) WPU, (b) WPU/POSS-5 wt $\%$ and (c) POSS
As indicated in Fig.5, the initial thermal decomposition temperature of POSS is $300{ }^{\circ} \mathrm{C}$ and maximum thermal decomposition temperature is $427^{\circ} \mathrm{C}$. After the temperature exceeds $700^{\circ} \mathrm{C}$, the residual weights is almost invariable, and the residue of POSS remains $42 \mathrm{wt} \%$. The WPU and WPU/ POSS hybrid films with different POSS loadings consisted of four stages of decomposition. The first stage occurring less than $200{ }^{\circ} \mathrm{C}$ presented a weight loss from $0 \%$ to $5 \%$ which is due to the loss of small molecules such as ethanol in the films. The curves of the WPU and WPU/POSS hybrid films were similar in this stage. In the second stage, the decomposition changed remarkably from $200{ }^{\circ} \mathrm{C}$ to $380{ }^{\circ} \mathrm{C}$ shown in Fig.5(b) and the weight loss was approximately $30 \%$ that was attributed to the cleavage of the urethane linkages. In the third stage, temperature ranged from $380^{\circ} \mathrm{C}$ to $600^{\circ} \mathrm{C}$, the thermal degradation of the WPU and WPU/POSS films with different POSS loadings changed significantly, which is due to the breakdown of the hydrocarbon in the soft and hard segment phases of the polyurethane structure ${ }^{46}$. The maximum degradation temperature is increased from $463^{\circ} \mathrm{C}$ to $483^{\circ} \mathrm{C}$ with the increasing of POSS loading which was attributed to the inorganic silicon element with higher heat resistance and the chemical bonds formed by Si-O-Si have higher bond energies. Furthermore, the small inorganic components in size easily infiltrate into the free volume of organic phase that is conducive to the reduction of free volume and result in a strong interaction between the two phases in the organic-inorganic hybrid system. In the last stage at over $600{ }^{\circ} \mathrm{C}$, the residual weights of the WPU/ POSS-5\%, WPU/POSS-10\%, WPU/POSS-15\% hybrid films were $5 \%, 8 \%, 12 \%$, respectively, which are greater than $3 \%$ of WPU film. The more the amount of POSS added, the better thermal stability and the more residual weight of the film was. The incorporation of silica and the Si-O-Si cross-linked structure can reduce the amount of combustible organic components and produce siliceous residue barrier layers that inhibit heat and mass transfer, which contributed to the increased thermal stability ${ }^{50}$.

\subsection{Mechanical properties of WPU/POSS hybrid films}

The hardness and Young's modulus at maximum load were used to evaluate the mechanical properties of the WPU and WPU/POSS hybrid films, and the results are summarized in Fig. 6. The pure WPU displayed hardness and Young's modulus of approximately 0.125 and $3.556 \mathrm{GPa}$, respectively. The WPU/POSS hybrids exhibited enhanced hardness and Young's modulus values with increasing POSS content. The hardness value at maximum load in WPU/POSS-5\%, WPU/ POSS- $10 \%$ and WPU/POSS- $15 \%$ was 3,5 and 6 times that of pure WPU, respectively. Furthermore, the Young's modulus values were 2.161, 4.301 and $6.367 \mathrm{GPa}$ greater than that of pure WPU. The increase in the hardness and Young's modulus can be interpreted on the basis of the reinforcement of the 


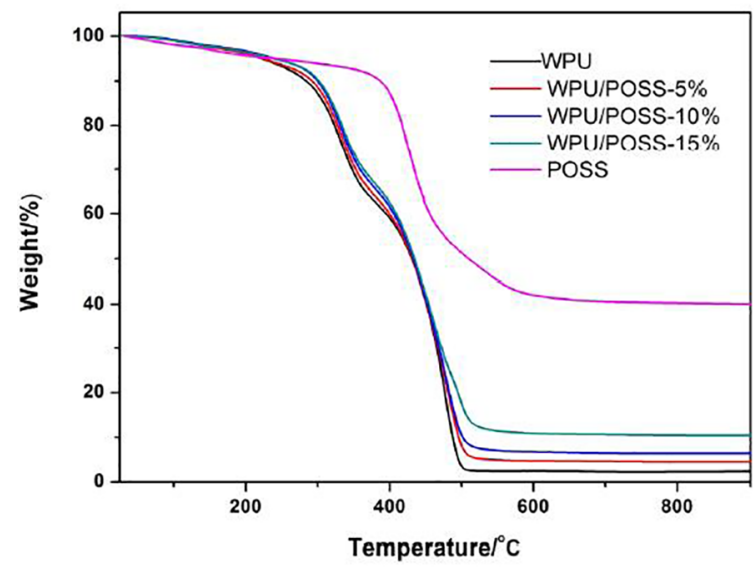

(a) TGA curves

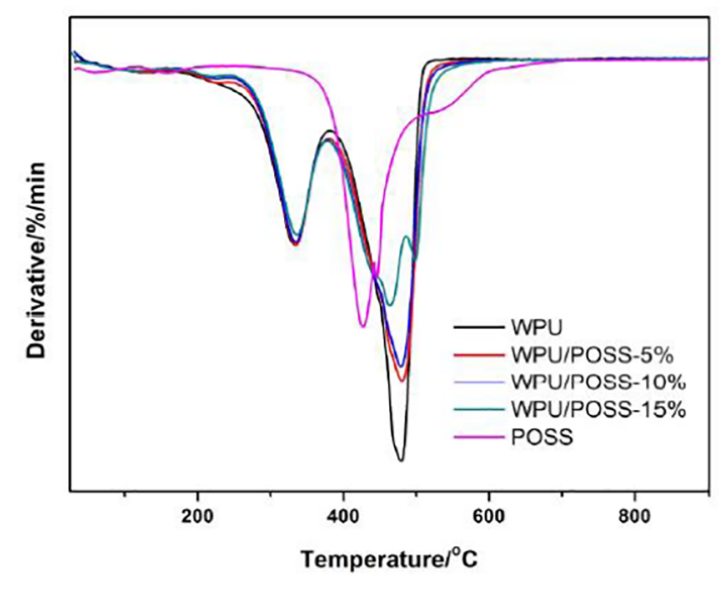

(b) DTG curves

Figure 5. (a) TGA curves for WPU, POSS and WPU/POSS hybrid films (b) DTG curves for WPU, POSS and WPU/POSS hybrid films

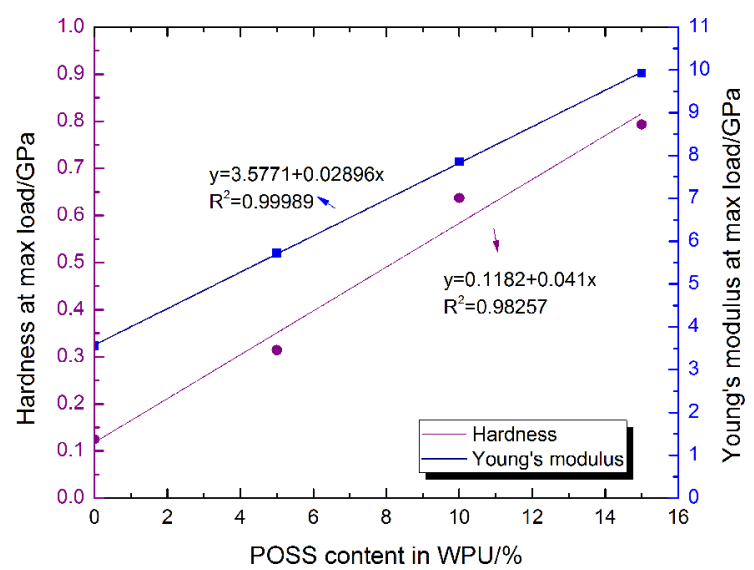

Figure 6. Hardness and Young's modulus at max load in different POSS/WPU specimens

POSS structure in the polymer matrices, which restricts the motion of macromolecular chains. The POSS content in the WPU/POSS hybrid films had a significant effect on the mechanical properties.

As shown in Fig. 6, with the increase of POSS content in WPU, Young's modulus and hardness showed a highly linear relationship. The variance $\mathrm{R}^{2}$ was 0.99989 and 0.98257 , respectively. The following equation predicts hardness as a function of inherent properties of the polymer nanocomposites and is known as the Kohlstedt equation (Eq. (1)): ${ }^{52}$

$$
H B=[0.07+0.6 \ln (E / \sigma)] \sigma
$$

where $E$ and $\sigma$ are Young's modulus and yield stress, respectively. As indicated by Eq. (1), the hardness value is proportional to the elastic modulus.

\subsection{Morphologies of POSS and WPU/POSS hybrid particles}

Figs. 7(a) and 7(b) present TEM images of POSS dispersed in water and the WPU coating with $5 \mathrm{wt} \%$ loading, respectively. Fig. 7(a) shows that the POSS particles were homogeneously dispersed in the aqueous solution at the nanometre level. Fig. 7(b) shows some small clusters composed of POSS particles dispersed in the WPU coating. Furthermore, the POSS nanoparticles were tightly packed for the $10 \mathrm{wt} \%$ loading, as observed in Fig. 7(c). Given the presence of a large number of polar hydroxyl groups on the surface of the POSS nanoparticles, good adsorption was achieved via hydrogen bonding. However, excess nano POSS in the system with more than $10 \mathrm{wt} \%$ loading led to excessive packing of particles, with clear agglomeration observed. The aggregation was associated with interactions between hydroxyl and epoxy groups of POSS molecule. SEM micrographs of WPU films with POSS loadings of (a) $0 \mathrm{wt} \%$ and (b) $5 \mathrm{wt} \%$ loading are shown in Fig. 8 . No obvious difference was observed in these two images. The surface of the modified film was uniform and no particles were agglomerated. Further observation of the cross section of the modified film (Fig. 9) revealed a large number of white particles distributed evenly. The surface elements were analysed (Fig. 10) and silicon was found in the white particles. The presence of silicon indicated that POSS particles were present in the polyurethane coatings and that an organic-inorganic hybrid system is formed.

\subsection{Performance of WPU and WPU/POSS hybrid films}

The pull-off adhesion tests of the coating were performed to measure the adhesion strength between wood and the 


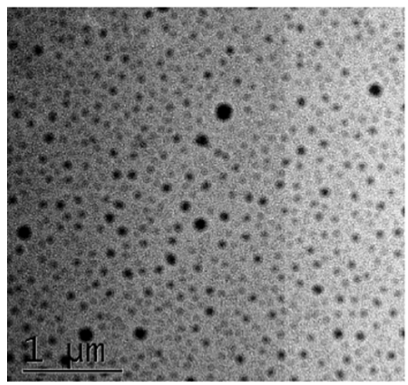

(a) POSSs in water

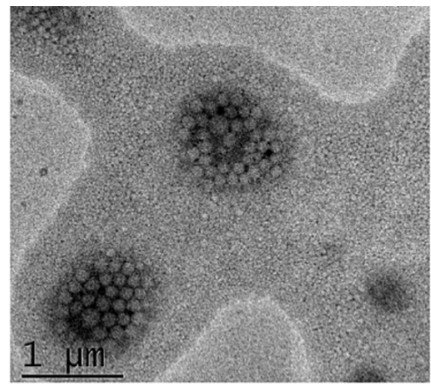

(b) 5 wt\% POSSs in WPU coatings

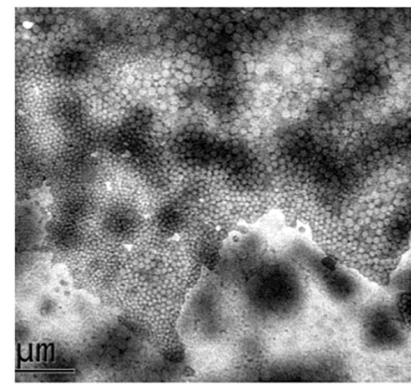

(c) 10 wt\% POSSs in WPU coatings

Figure 7. (a) Morphology of POSS particles in water (b) Morphology of POSS particles in WPU coatings with 5 wt $\%$ loading (c) Morphology of POSS particles in WPU coatings with $10 \mathrm{wt} \%$ loading

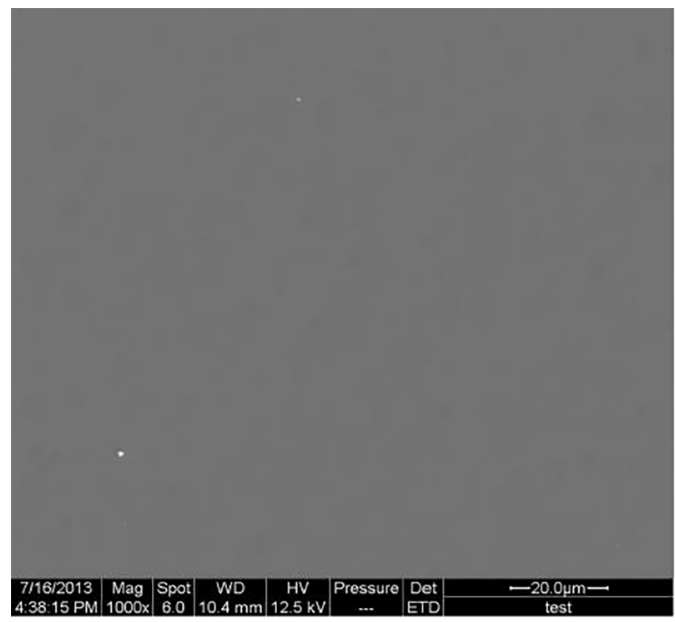

(a) 0 wt\% POSS loadings

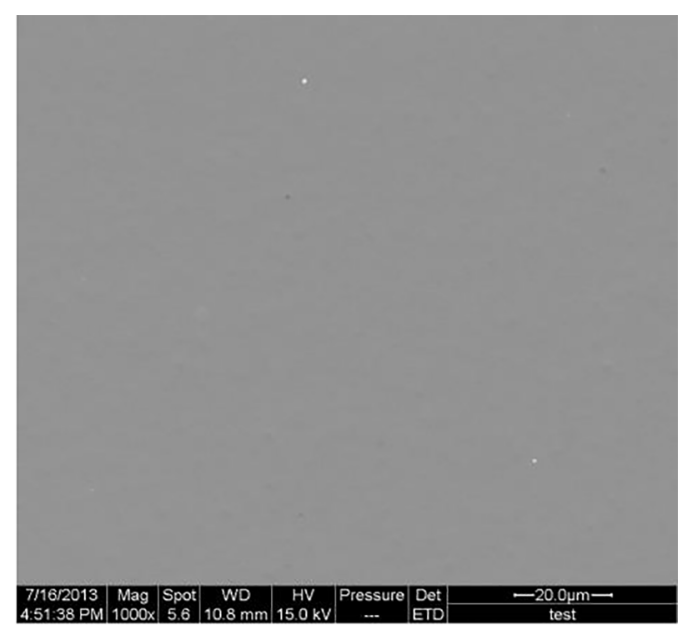

(b) 5 wt\% POSS loadings

Figure 8. (a) Morphology of WPU films with POSS loadings of $0 \mathrm{wt} \%$ (b) Morphology of WPU films with POSS loadings of $5 \mathrm{wt} \%$
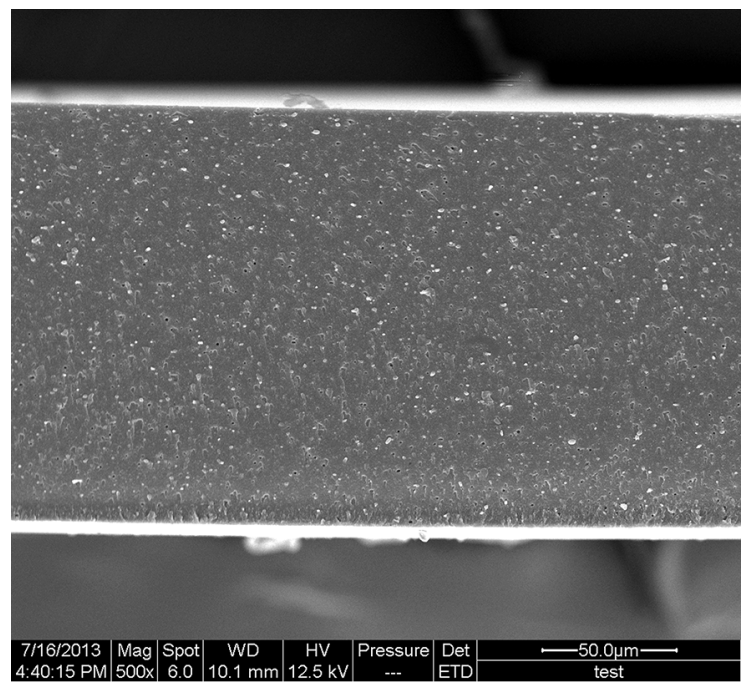

Figure 9. Cross-sectional film with a POSS $5 \mathrm{wt} \%$ loading

coating, and the results are presented in Table 2. The pure WPU coating exhibited adhesion values of Grade 0 . The addition of POSS slightly decreased the adhesion of the coating on wood from Grade 1 to 2 . Adhesion strength is

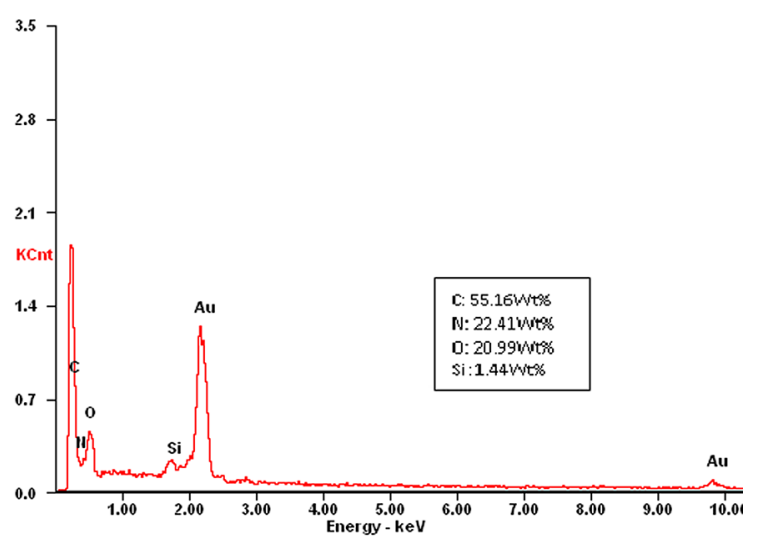

Figure 10. Element surface analysis of the white particles shown in Fig. 9

not only related to the crosslinking of WPU with hydroxyl groups on the wood surface but also to the spreading wettability and penetrability of the liquid coatings on the surface. With increasing POSS loading, the viscosity of the coatings increased which limited their ability to penetrate into the wood pores. Wood is a biomass material made up 
Table 2.. Comparison of film performance for various POSS contents

\begin{tabular}{cccc}
\hline Sample & $\begin{array}{c}\text { Adhesion / } \\
\text { grade }\end{array}$ & $\begin{array}{c}\text { Pencil } \\
\text { hardness / } \\
\text { grade }\end{array}$ & $\begin{array}{c}\text { Abrasion } \\
\text { resistance /g }\end{array}$ \\
\hline $\begin{array}{c}\text { WPU } \\
\text { WPU/POSS- } \\
5 \%\end{array}$ & 0 & $\mathrm{H}$ & 0.04 \\
$\begin{array}{c}\text { WPU/POSS- } \\
10 \%\end{array}$ & 2 & $3 \mathrm{H}$ & 0.036 \\
$\begin{array}{c}\text { WPU/POSS- } \\
15 \%\end{array}$ & 2 & $3 \mathrm{H}$ & 0.032 \\
\hline
\end{tabular}

of numerous cells, and its surface is covered with pores. The low-viscosity coatings exhibit good fluidity and good penetrability on the surface of the wood. Consequently, the coatings can form a large number of anchors on the wood which results in highly improved adhesion. By contrast, the coatings with high viscosity exhibited poor wettability and poor penetrability which led to lower adhesion.

Hardness is an important property of the coating that is related to durability and long-term performance. The results in Table 2 clearly show that the pencil hardness increased with increasing POSS content; this phenomenon can be mainly attributed to the increase in Young's modulus. The hardness performance has been widely reported to be affected by the degree of crosslinking, network density and polymer module ${ }^{53}$. The increase in the hardness and Young's modulus results can be correlated to better distribution and crosslinking of POSS particles in the POSS/WPU hybrid films. The epoxy group and $\mathrm{Si}-\mathrm{OH}$ in POSS produce the $3 \mathrm{D}$ crosslinking with the urethane or hydroxyl groups in WPUs which increases the crosslinking density between the organic and inorganic moieties. The results indicate that POSS molecules were incorporated into the polymer chain as molecular reinforcements in the hard segment.

Abrasion resistance is represented by the loss amount of the coating. The results in Table 2 show that the loss amount of the coatings gradually decreased with increasing POSS content, thus indicating that the coating abrasion resistance was enhanced by the addition of POSS particles which was attributed to the use of POSS with Si-O-Si inorganic chains and to crosslinking between POSS and WPU. POSS framework closely resembles that of silica; silsesquioxanes can form hard, abrasion-resistant coatings. Furthermore, the reaction of active groups between POSS and WPU increases the crosslinking density and contributes to the mechanical interlock between the polymer chains.

\section{Conclusions}

The improvement of the properties and performance of WPU coatings with the addition of POSS as a reinforcing agent was investigated. FT-IR analysis confirmed the presence of hydrogen bonding and chemical crosslinking between the WPU and POSS. The POSS components retained their partial structure, thus improving the thermal stability and mechanical properties of the hybrid films compared with the pure WPU coating. An appropriate loading of $5 \mathrm{wt} \%$ of POSS was essential to achieve a dispersed system and avoid the excessive packing of the particles in the WPU. Furthermore, the pencil hardness was improved significantly to $3 \mathrm{H}$ and the abrasion resistance gradually increased with increasing POSS content; however, the pull-off adhesion slightly decreased from Grade 0 to Grade 2.

\section{Acknowledgements}

This work was supported by the Key Laboratory of Bio-based Material Science \& Technology (Northeast Forestry University), the Ministry of Education (grant number SWZCL2016-14), the Fundamental Research Funds for the Central Universities grant number 2572017CB19, 2572017EB06, and 2572018CP01.

\section{References}

1. Yang CH, Liu FJ, Liu YP, Liao WT. Hybrids of colloidal silica and waterborne polyurethane. Journal of Colloid and Interface Science. 2006;302(1):123-132.

2. Althues H, Henle J, Kaskel S. Functional inorganic nanofillers for transparent polymers. Chemical Society Reviews. 2007;36(9):14541465 .

3. Chattopadhyay DK, Raju KVSN. Structural engineering of polyurethane coatings for high performance applications. Progress in Polymer Science. 2007;32(3):352-418.

4. Liu H, Cui SQ, Shang S, Wang D, Song J. Properties of rosin-based waterborne polyurethanes/cellulose nanocrystals composites. Carbohydrate Polymers. 2013;96(2):510-515.

5. Rahman MM, Kim HD, Lee WK. Preparation and characterization of waterborne polyurethane/clay nanocomposite: Effect on water vapor permeability. Journal of Applied Polymer Science. 2008;110(6):3697-3705.

6. Lee SK, Yoon SH, Chung I, Hartwig A, Kim BK. Waterborne polyurethane nanocomposites having shape memory effects. Journal of Polymer Science Part A Polymer Chemistry. 2011;49(3):634-641.

7. Wang X, Xing WY, Song L, Yang HY, Hu Y, Yeoh GH. Fabrication and characterization of graphene-reinforced waterborne polyurethane nanocomposite coatings by the sol-gel method. Surface \& Coatings Technology. 2012;206(23):4778-4784.

8. Dhoke SK, Bhandari R, Khanna AS. Effect of nano-ZnO addition on the silicone-modified alkyd-based waterborne coatings on its mechanical and heat-resistance properties. Progress in Organic Cotings. 2009;64(1):39-46.

9. Shi X, Nguyen TA, Suo Z, Liu Y, Avci R. Effect of nanoparticles on the anticorrosion and mechanical properties of epoxy coating. Surface \& Coatings Technology. 2009;204(3):237-245. 
10. Sow C, Riedl B, Blanchet P. UV-waterborne polyurethaneacrylate nanocomposite coatings containing alumina and silica nanoparticles for wood: mechanical, optical, and thermal properties assessment. Journal of Coatings Technology and Research. 2011;8(2):211-221.

11. Ramli RA, Laftah WA, Hashim S. Core-shell polymers: a review. RSC Advances. 2013;3(36):15543-15565.

12. Veigel S, Grüll G, Pinkl S, Obersriebnig M, Müller U, GindlAltmutter W. Improving the mechanical resistance of waterborne wood coatings by adding cellulose nanofibres. Reactive \& Functional Polymers. 2014;85:214-220.

13. Xu K, Zhou S, Wu L. Dispersion of ?methacryloxypropyltrimet hoxysilane-functionalized zirconia nanoparticles in UV-curable formulations and properties of their cured coatings. Progress in Organic Coatings. 2010;67(3):302-310.

14. Song CM, Yuan QL, Wang DN. Effect of the content of urea groups on the particle size in water-borne polyurethane or polyurethane/polyacrylate dispersions. Colloid and Polymer Science. 2004;282(6):642-645.

15. Naghash HJ, Abili B. RETRACTED: Synthesis of a silicone containing allylic monomer and its uses in the waterborne polyurethane/vinyl acetate-acrylic hybrid emulsion copolymers. Progress in Organic Coatings. 2010;69(4):486-494.

16. Cao XD, Habibi Y, Lucia LA. One-pot polymerization, surface grafting, and processing of waterborne polyurethane-cellulose nanocrystal nanocomposites. Journal of Materials Chemistry. 2009;19(38):7137-7145.

17. Gao ZZ, Peng J, Zhong TH, Sun J, Wang XB, Yue C. Biocompatible elastomer of waterborne polyurethane based on castor oil and polyethylene glycol with cellulose nanocrystals. Carbohydrate Polymers. 2012;87(3):2068-2075.

18. Wang YH, Tian HF, Zhang LN. Role of starch nanocrystals and cellulose whiskers in synergistic reinforcement of waterborne polyurethane. Carbohydrate Polymers. 2010;80(3):665-671.

19. Lee SJ, Kim BK. Covalent incorporation of starch derivative into waterborne polyurethane for biodegradability. Carbohydrate Polymers. 2012;87(2):1803-1809.

20. Nikje MMA, Tehrani ZM. Synthesis and Characterization Of Waterborne Polyurethane-Chitosan Nanocomposites. PolymerPlastics Technology and Engineering. 2010;49(8):812-817.

21. Helbert W, Cavaillé JY, Dufresne A. Thermoplastic nanocomposites filled with wheat straw cellulose whiskers. Part I: Processing and mechanical behavior. Polymer Composites. 1996;17(4):604611.

22. Grüneberger F, Künniger T, Zimmermann T, Arnold M. Rheology of nanofibrillated cellulose/acrylate systems for coating applications. Cellulose. 2014;21(3):1313-1326.

23. Grüneberger F, Künniger T, Huch A, Zimmermann T, Arnold M. Nanofibrillated cellulose in wood coatings: Dispersion and stabilization of $\mathrm{ZnO}$ as UV absorber. Progress in Organic Coatings. 2015;87:112-121.

24. Kaushik A, Singh M, Verma G. Green nanocomposites based on thermoplastic starch and steam exploded cellulose nanofibrils from wheat straw. Carbohydrate Polymers. 2010;82(2):337345 .
25. Littunen K, Hippi U, Saarinen T, Seppälä J. Network formation of nanofibrillated cellulose in solution blended poly(methyl methacrylate) composites. Carbohydrate Polymers. 2013;91(1):183190.

26. Virtanen S, Vartianen J, Setälä H, Tammelin T, Vuoti S. Modified nanofibrillated cellulose-polyvinyl alcohol films with improved mechanical performance. RSC Advances. 2014;4:11343-11350.

27. Khelifa F, Habibi Y, Benard F, Dubois P. Effect of cellulosic nanowhiskers on the performances of epoxidized acrylic copolymers. Journal of Materials Chemistry. 2012;22(38):2052020528.

28. Pu Y, Zhang J, Elder T, Deng Y, Gatenholm P, Ragauskas AJ. Investigation into nanocellulosics versus acacia reinforced acrylic films. Composites Part B: Engineering. 2007;38(3):360-366.

29. Wu Q, Henriksson M, Liu L, Berglund LA. A High Strength Nanocomposite Based on Microcrystalline Cellulose and Polyurethane. Biomacromolecules. 2007;8(12):3687-3692.

30. Xu X, Liu F, Jiang L, Zhu JY, Haagenson D, Wiesenborn DP. Cellulose Nanocrystals vs. Cellulose Nanofibrils: A Comparative Study on Their Microstructures and Effects as Polymer Reinforcing Agents. ACS Applied Materials \& Interfaces. 2013;5(8):29993009 .

31. Yao X, Qi X, He Y, Tan D, Chen F, Fu Q. Simultaneous Reinforcing and Toughening of Polyurethane via Grafting on the Surface of Microfibrillated Cellulose. ACS Applied Materials \& Interfaces. 2014;6(4):2497-2507.

32. Zhang H, She Y, Song S, Chen H, Pu J. Improvements of mechanical properties and specular gloss of polyurethane by modified nanocrystalline cellulose. BioResources. 2012;7(4):51905199 .

33. Poaty B, Vardanyan V, Wilczak L, Chauve G, Riedl B. Modification of cellulose nanocrystals as reinforcement derivatives for wood coatings. Progress in Organic Coatings. 2014;77(4):813-820.

34. Jeon HT, Jang MK, Kim BK, Kim KH. Synthesis and characterizations of waterborne polyurethane-silica hybrids using sol-gel process. Colloids and Surfaces A-Physicochemical and Engineering Aspects. 2007;302(1-3):559-567.

35. Pei A, Malho JM, Ruokolainen J, Zhou Q, Berglund LA. Strong Nanocomposite Reinforcement Effects in Polyurethane Elastomer with Low Volume Fraction of Cellulose Nanocrystals. Macromolecules. 2011;44(11):4422-4427.

36. Cheng D, Wen YB, An XY, Zhu XH, Ni YH. TEMPO-oxidized cellulose nanofibers (TOCNs) as a green reinforcement for waterborne polyurethane coating (WPU) on wood. Carbohydrate Polymers. 2016;151:326-334.

37. Qu JQ, Li YJ, Chen HQ. Development Progress of Aqueous $2 \mathrm{~K}$ Polyurethane Coatings. Paint \& Coatings Industry. 2002;11:34 37.

38. Zhang XG, Chen KF, Ye ZJ. Progress in Research of Application of POSS in Coatings. Development and Application of Materials. 2013;28(1):90-95.

39. Hu Y, Wang Y, You H, Wang D. Hedgehog Buckyball: A HighSymmetry Complete Polyhedral Oligomeric Silsesquioxanes (POSS). Polymers. 2016;8:315. 
40. Wang YY, Qiu FX, Lv YF, Xu JC, Yang DY. Preparation and properties of waterborne poly(urethane acrylate)/silica dispersions and hybrid composites. Plastics, Rubber and Composites. 2012;41(10):418-424.

41. Wu D, Xu H, Qiu F, Yang D. Preparation, Morphology and Properties of Waterborne-Polyurethane/Silica. Polymer-Plastics Technology and Engineering. 2011;50(5):498-508.

42. .Wu Y, Du Z, Wang H, Cheng X. Synthesis of aqueous highly branched silica sol as underlying crosslinker for corrosion protection. Progress in Organic Coatings. 2017;111:381-388.

43. Madbouly SA, Otaigbe JU. Recent advances in synthesis, characterization and rheological properties of polyurethanes and POSS/polyurethane nanocomposites dispersions and films. Progress in Polymer Science. 2009;34(12):1283-1332.

44. Cordes DB, Lickiss PD, Rataboul F. Recent Developments in the Chemistry of Cubic Polyhedral Oligosilsesquioxanes. Chemical Reviews. 2010;110(4):2081-2173.

45. Kannan RY, Salacinski HJ, Butler PE, Seifalian AM. Polyhedral Oligomeric Silsesquioxane Nanocomposites: The Next Generation Material for Biomedical Applications. Accounts of Chemical Research. 2005;38(11):879-884.

46. Wang WP, Ding WL, Lv XY, Yu J, Jiang H. Synthesis and Properties of POSS Modified Polyurethane. Polymeric Materials Science and Engineering. 2013;29(1):40-43.

47. Liu G, Wu G, Chen J, Huo S, Jin C, Kong Z. Synthesis and properties of POSS-containing gallic acid-based non-isocyanate polyurethanes coatings. Polymer Degradation and Stability. 2015;121:247-252.
48. Lai YS, Tsai CW, Yang HW, Wang GP, Wua KH. Structural and electrochemical properties of polyurethanes/polyhedral oligomeric silsesquioxanes (PU/POSS) hybrid coatings on aluminum alloys. Materials Chemistry and Physics. 2009;117(1):91-98.

49. Li X, Hu J, Sun D, Zhang Y. Nanosilica reinforced waterborne siloxane-polyurethane nanocomposites prepared via "click" coupling. Journal of Coatings Technology and Research. 2014;11(4):517-531.

50. Williams RJJ, Erra-Balsells R, Ishikawa Y, Nonami H, Mauri AN, Riccardi CC. UV-MALDI-TOF and ESI-TOF Mass Spectrometry Characterization of Silsesquioxanes Obtained by the Hydrolytic Condensation of (3-Glycidoxypropyl)trimethoxysilane in an Epoxidized Solvent. Macromolecular Chemistry and Physics. 2001;202(11):2425-2433.

51. ASTM International. ASTM-D-1474-98 - Standard Test Methods for Indentation Hardness of Organic Coatings. West Conshohocken: ASTM International; 2002.

52. Malaki M, Hashemzadeh Y, Karevan M. Effect of nanosilica on the mechanical properties of acrylic polyurethane coatings. Progress in Organic Coatings. 2016;101:477-485.

53. Espino-Pérez E, Bras J, Ducruet V, Guinault A, Dufresne A, Domenek S. Influence of chemical surface modification of cellulose nanowhiskers on thermal, mechanical, and barrier properties of poly(lactide) based bionanocomposites. European Polymer Journal. 2013;49(10):3144-3154. 